\title{
Imobilização de fraturas femorais em gatos usando pino intramedular conectado ou não ao fixador esquelético externo
}

\author{
Immobilization of femoral fractures in cats using intramedullary pin tied-in \\ or not with the external skeletal fixator \\ Sheila Canevese Rahal ${ }^{1}$ Maria Isabel Garib ${ }^{2}$ Fabiana Mitie Matsubara ${ }^{3}$ \\ Luiz Carlos Vulcano ${ }^{4}$ Mario Jefferson Quirino Louzada ${ }^{5}$
}

\section{RESUMO}

\begin{abstract}
O trabalho teve por objetivo comparar a consolidação óssea e a função do membro, em 18 gatos com fraturas transversas femorais tratadas com pino intramedular e fixador esquelético externo tipo Ia (grupo I, n=9) ou com pino intramedular associado ao fixador externo em uma configuração "tie-in" (grupo II, $n=9$ ). Independente da configuração utilizada, após a remoção dos implantes, todos os animais apresentaram função normal do membro operado. Não houve diferença entre os grupos em relação à densidade mineral óssea do calo externo mensurada pela densitometria óptica por imagens radiográficas. O tempo para consolidação foi significativamente maior para as fraturas tratadas com pino intramedular e fixador tipo Ia. As fraturas que receberam a configuração "tie-in" tiveram menos proliferação de calo ósseo.
\end{abstract}

Palavras-chave: gatos, fixador, fratura, fêmur.

\section{ABSTRACT}

The aim of this study was to compare bone healing and limb function in 18 cats with transverse femoral fractures treated with either intramedullary pin and a type Ia external skeletal fixator (Group 1, $n=9$ ) or a tie-in configuration (Group 1, n=9). All animals showed normal function of the operated limb after implant removal, independently of the configuration used. The optic bone densitometry in radiographic images showed no difference in bone mineral density of the external bone callus between the groups. Fractures treated with intramedullary pin and type Ia external fixator had significantly more time to fracture healing, and fractures treated with the tie-in configuration had less proliferation of bone callus.

Key words: cats, fixator, fracture, femur.

\section{INTRODUÇÃO}

As fraturas de fêmur em gatos são freqüentemente tratadas utilizando-se pinos intramedulares, associação de pinos intramedulares e fios, ou fixação esquelética externa (OLMSTEAD, 1995; PIERMATTEI \& FLO, 1997). Se a estabilidade não pode ser obtida apenas com pino intramedular e fios ortopédicos, acrescenta-se um fixador externo tipo Ia ou Ib (OLMSTEAD, 1995; JOHNSON \& HULSE, 2002). As indicações mais comuns para essa combinação são as fraturas transversas, oblíquas curtas e as minimamente cominutivas (WHITEHAIR \& VASSEUR, 1992).

O fixador resiste às cargas de torção, cisalhamento e compressão, e o pino intramedular controla o envergamento (ARON et al., 1991; JOHNSON \& HULSE, 2002). A força e a rigidez da montagem podem ser influenciadas pela configuração e pelo número dos pinos de transfixação (JOHNSON \& HULSE, 2002). Entretanto, em fraturas femorais o número de pinos é limitado a um ou dois aplicados nas porções proximal e distal à fratura, para reduzir o desconforto da colocação através de grandes grupos musculares (WHITEHAIR \& VASSEUR, 1992; JOHNSON \& HULSE, 2002).

Entre as estratégias para combater as forças axial e de envergamento no local da fratura e, ao mesmo tempo, minimizar o número de pinos de transfixação estão a colocação de uma barra externa adicional, ou a

\footnotetext{
${ }^{1}$ Médico Veterinário, Professor Adjunto, Departamento de Cirurgia e Anestesiologia Veterinária, Faculdade de Medicina Veterinária e Zootecnia (FMVZ), Universidade Estadual Paulista (UNESP) Botucatu. Rubião Júnior s/n, 18618000, Botucatu, SP. Email: sheilacr@fmvz.unesp.br.Autor para correspondência.

${ }^{2}$ Médico Veterinário, Bolsista de Treinamento Técnico-Nível 3.

${ }^{3}$ Médico Veterinário, Doutorando em Cirurgia Veterinária, FMVZ, UNESP Botucatu.

${ }^{4}$ Médico Veterinário, Professor Adjunto, Departamento de Reprodução Animal e Radiologia Veterinária, FMVZ, UNESP Botucatu.

${ }^{5}$ Físico, Curso de Medicina Veterinária, UNESP Araçatuba. Rua José Bonifácio, 1193, 16015050, Araçatuba, SP.
} 
conexão do pino intramedular ao fixador em configuração denominada "tie-in" (ANDERSON \& ARON, 1998; JOHNSON \& HULSE, 2002). Nesse tipo de configuração, a extremidade proximal do fixador tipo I pode, por exemplo, ser conectada na extremidade proximal de um pino intramedular de tamanho apropriado usando uma barra adicional e grampos conectantes duplos. Com isto, aumenta-se a força de envergamento da montagem e reduz-se a incidência de complicações pós-operatórias (ARON et al., 1991; OLMSTEAD et al., 1995).

Ao tratarem 13 fraturas femorais em gatos com pino intramedular e fixador externo em configuração “tie-in”, ARON et al. (1991) não verificaram complicações relacionadas com o pino intramedular exposto, havendo mínima reação tecidual. Além disso, os animais pareciam confortáveis.

LANGLEY-HOBBS et al. (1996) utilizaram três formas de montagens no tratamento de diversos tipos de fraturas femorais em gatos. No grupo A, empregaram fixador unilateral aplicado junto com um pino intramedular, no grupo B, apenas fixador unilateral e, no grupo $\mathrm{C}$, o fixador unilateral foi associado com um pino intramedular "tie-in". Os autores concluíram que todos os métodos foram úteis e que a média para a remoção do fixador foi oito semanas e dois dias.

Um fixador externo tipo Ia foi usado em conjunto com pino intramedular por FOLAND et al. (1991), no tratamento de fraturas do fêmur em 14 gatos. A freqüência de complicações foi de $43 \%$, sendo consideradas como maiores a lesão do quadríceps e a fratura secundária da tíbia, e menores a união retardada, a osteomielite e a perda da redução/fixação da fratura. A maioria dos animais não reassumiu o completo suporte de peso no membro afetado até a retirada do fixador externo, sendo o êxito final de $93 \%$.

O fixador externo pode ser removido após quatro a seis semanas, caso ocorra a formação de calo fibroso (OLMSTEAD et al., 1995). EGGER et al. (1993) observaram, em estudo experimental com cães, que a desestabilização de um fixador rígido após uma ou quatro semanas causou aumento da formação de calo periosteal com diminuição da força mecânica, e com seis semanas produziu maior força mecânica sem interferir no calo periosteal. A desestabilização após 12 semanas não teve influência no processo de consolidação.

O padrão de consolidação óssea depende da fratura e da rigidez do fixador (JOHNSON et al., 1998). Geralmente uma fratura tratada com um fixador relativamente flexível permite algum movimento interfragmentário com mais proliferação de calo periosteal. Uma fratura bem reduzida com fixação muito rígida freqüentemente promove a união óssea direta (OLMSTEAD et al., 1995; JOHNSON et al., 1998).

O trabalho teve por objetivo comparar a função do membro e a consolidação óssea em gatos com fraturas transversas femorais, tratadas com pino intramedular e fixador esquelético externo tipo Ia ou com pino intramedular associado ao fixador externo em configuração "tie-in".

\section{MATERIAL E MÉTODOS}

Foram utilizados 17 gatos sem raça definida e um Siamês, 12 fêmeas e seis machos, com idade média de 1,5 anos e peso inicial médio de $3,1 \mathrm{~kg}$. Posterior à vacinação e vermifugação, os animais foram castrados, divididos por sorteio em dois grupos experimentais eqüitativos (I e II) e confinados em gaiolas, com água fresca e ração comercial ad libitum. Numeraram-se os gatos do grupo I de um a nove e os do grupo II de 10 a 18, e, no final do experimento, todos foram doados.

Após jejum de 12 horas, a indução anestésica foi realizada com associação de cloridrato de cetamina ( $15 \mathrm{mg} \mathrm{kg}^{-1}$, IM) e midazolam $\left(1 \mathrm{mg} \mathrm{kg}^{-1}\right.$, IM) e a manutenção com halotano. Cada animal foi contido na mesa, em decúbito lateral direito, e com o membro posterior esquerdo preparado para cirurgia asséptica. A diáfise femoral foi abordada por acesso lateral entre os músculos bíceps femoral e vasto lateral. Os músculos vasto intermédio e adutor da coxa foram separados e afastados sem o periósteo, $1 \mathrm{~cm}$ na porção média do fêmur, para expor a diáfise femoral. Em seguida, induziu-se fratura transversa da diáfise média por meio de serra giratória.

Nos animais do grupo I, a fratura foi estabilizada inicialmente por um pino intramedular de Steinmann com diâmetro entre 55-60\% do istmo do canal femoral. Este foi aplicado de forma retrógrada e o excesso externo, cortado. Na seqüência, aplicou-se um fixador externo tipo $\mathrm{Ia}^{\mathrm{a}}$. O pino externo proximal foi inserido da superfície lateral do trocanter maior até a córtex medial próxima à base do colo femoral. O pino externo distal foi aplicado da superfície lateral para a medial, na junção da diáfise e metáfise. Por serem pinos com ponta rosqueada de perfil positivo ${ }^{\text {b }}$ (diâmetro da haste de 2,4mm e diâmetro da rosca de 3,2mm), primeiro, efetuouse perfuração óssea com broca e protetor, para posterior inserção com perfurador manual de Jacobs. Os pinos proximal e distal foram unidos a uma barra conectante e os grampos apertados a uma distância de $1 \mathrm{~cm}$ da pele. A fáscia lata e a borda cranial do músculo bíceps foram aproximadas com sutura contínua simples, o tecido 
subcutâneo com sutura contínua simples e a pele com pontos simples isolados, utilizando-se fio de náilon 40 . No grupo II, o procedimento cirúrgico foi semelhante ao do grupo I. No entanto, o pino intramedular ficou exposto na porção proximal e foi conectado ao fixador externo (uniplanar tipo Ia) por meio de dois grampos e uma barra conectante curta, em configuração "tie-in".

Com oito semanas, removeu-se o fixador externo nos gatos do grupo I e o pino de transfixação distal nos do grupo II. Com a evidência radiográfica da consolidação óssea, foram removidos o pino intramedular no grupo I e o pino intramedular e o pino de transfixação proximal no grupo II. Os animais foram avaliados por mais quatro semanas após a retirada de todos os implantes.

Antes do início da cirurgia e por mais sete dias no período pós-operatório, foi aplicada ampicilina benzatina na dose de $20 \mathrm{mg} \mathrm{kg}^{-1}$, por via subcutânea, a cada 24 horas. Buprenorfina $\left(0,01 \mathrm{mg} \mathrm{kg}^{-1}\right.$ a cada 8 ou 12 horas) e flunixina meglumina ( $1,1 \mathrm{mg} \mathrm{kgV}$ a cada 24 horas) foram usadas no pré-operatório imediato e por três dias no pós-operatório. Durante a evolução do experimento, estes últimos medicamentos foram repetidos isoladamente ou em conjunto, se detectado sinais de dor. O tratamento da ferida cirúrgica e dos locais de emergência dos pinos foi com solução antiséptica e aplicação tópica de solução de nitrofurazona. $\mathrm{O}$ fixador externo e os pinos ficaram protegidos por bandagem, trocada a cada três dias.

O peso corpóreo foi aferido antes e no final do experimento. No momento da troca de curativo, verificaram-se os locais de emergência dos pinos quanto à presença de secreção. $\mathrm{O}$ apoio do membro operado foi avaliado semanalmente, pela observação dos gatos em uma sala, de acordo com o seguinte critério: grau I - nenhum uso funcional do membro e/ ou marcada claudicação; grau II - membro funcional, mas freqüentemente claudica; modo de andar anormal; grau III - claudicação; uso funcional do membro; suporte parcial de peso; grau IV - normal; uso funcional total para permanecer em pé, caminhar e correr; suporte total do membro.

Os membros operados foram radiografados nas posições lateral e craniocaudal, antes e imediatamente após o procedimento cirúrgico, e a cada duas semanas até a consolidação óssea, estabelecida pela ausência de linha de fratura. O último controle foi realizado quatro semanas após. Realizouse densitometria óssea óptica em imagens radiográficas do foco de fratura (calo externo), segundo a técnica padronizada por LOUZADA (1994), na projeção craniocaudal, imediatamente após o procedimento cirúrgico, com oito e 12 semanas.
Foi empregado o teste $\mathrm{t}$ de Student (ZAR, 1996), visando comparar em média o efeito dos dois tratamentos no número de semanas para consolidação e ganho de peso relativo. Para as variáveis grau de locomoção, na época da retirada do fixador e semana inicial de locomoção constante em grau IV, foi utilizado o teste não paramétrico de MannWhitney. Para a densitometria óssea óptica radiográfica empregou-se a análise de variância com medida repetida e teste Tukey. Todos os testes foram realizados em nível de 5\% de significância.

\section{RESULTADOS}

O peso corpóreo final foi maior que o inicial. Em geral, foi verificada secreção serosa ou serossangüinolenta nos pontos de emergência dos pinos, mais evidente na primeira semana do póscirúrgico. A secreção no pino distal, especialmente no grupo I, foi mais intensa que no pino proximal. No grupo I, dois gatos (5 e 8) apresentaram, em torno de quatro semanas, secreção purulenta na região do pino distal. No grupo experimental II, foi observada secreção purulenta no ponto de emergência do pino intramedular em três gatos $(12,15$ e 18) com sete semanas e um com cinco semanas (16). O animal 11 apresentou infecção no trajeto do pino intramedular e do pino externo proximal com 11 semanas. Notou-se que em quatro gatos $(11,15,17$ e 18), o grampo conectante duplo do pino externo proximal estava frouxo, quando da apresentação da infecção. Além disso, ocorreu migração do pino intramedular nestes quatro animais. Em todos eles, o pino foi recalcado, porém, no animal 11, houve necessidade da remoção com 15 semanas por causa da recidiva associada à infecção. Para tratamento dos quadros infecciosos, utilizou-se ampicilina benzatina na dose $20 \mathrm{mg} \mathrm{kg}^{-1}$, por via subcutânea, durante sete a 10 dias.

Todos os gatos apoiavam o membro, com suporte parcial ou total do peso, desde o primeiro dia de pós-operatório (graus II e III). Quatro animais do grupo I apresentaram melhora da locomoção após a retirada do fixador externo. Um animal do grupo I (6) apresentou, no pós-operatório imediato, perda de propriocepção com apoio no dorso dos dígitos, dor acentuada e reflexo flexor diminuído. Com cinco semanas, ele voltou a apoiar o membro ao solo em posição anatômica, porém manteve o jarrete em hiperflexão. Após a remoção do fixador externo, houve melhora clínica, porém a completa recuperação somente ocorreu com a retirada do pino intramedular. Dois gatos do grupo II (10 e 13) locomoviam-se com hiperflexão do jarrete, rotação externa da pata e desvio do peso corpóreo 
para o membro contralateral e apresentavam diminuição da sensibilidade desde a articulação do tarso até a extremidade do membro. Esse tipo de deambulação se manteve por oito semanas, com melhora após a remoção do fixador externo e total recuperação com a retirada do pino intramedular. Não houve diferença de ganho de peso entre os grupos (Tabela 1) e entre as variáveis grau de locomoção, na época da retirada do fixador e na semana inicial de locomoção constante em grau IV (Tabela 2).

Nos dois grupos, com quatro e, mais evidente, com oito semanas de pós-operatório visibilizou-se formação de calo ósseo periosteal na face medial do foco de fratura em radiografias obtidas na posição craniocaudal. $\mathrm{Na}$ face lateral, o calo ósseo não foi muito evidente. Em média, a formação do calo ósseo periosteal, nos animais do grupo I (Figura 1), foi maior que a do grupo II (Figura 2). Foram observadas três translações do foco de fratura no grupo I (1, 5 e 9) e uma no grupo II (13), detectadas geralmente no controle radiográfico efetuado com duas semanas de pós-operatório. Em dois animais do grupo I (3 e 5), não foi possível retirar o pino intramedular, uma vez que ele estava profundamente assentado. No grupo I, foi verificado, com quatro semanas, osteólise ao redor do pino distal nos animais 5 e 8 e, com oito semanas, no pino distal dos gatos 1 e 2 e pino externo proximal do 3. No grupo II, notou-se, no animal 11, osteólise ao redor do pino externo proximal com 12 semanas e, no gato 17, com oito semanas. Na última avaliação radiográfica do gato 15 , observou-se não-união hipertrófica. $\mathrm{O}$ número de semanas para consolidação foi maior no grupo experimental I (Tabela 1). Não houve efeito significativo de momento, grupo, posição e idade na densitometria óssea óptica em imagens radiográficas.

\section{DISCUSSÃO}

O apoio do membro desde o primeiro dia de pós-operatório, indica boa tolerância dos animais aos fixadores externos, fato também verificado

Tabela 1 - Médias (desvio-padrão) segundo grupos (G I - pino intramedular e fixador tipo Ia; G II - pino intramedular e fixador externo em configuração "tiein) e variáveis avaliadas (ganho de peso e numero de semanas para consolidação).

\begin{tabular}{lcc}
\hline & Média & Desvio padrão \\
\hline \multirow{2}{*}{ Ganho de peso relativo } & (G I) 23\%a & 0,202 \\
& (G II) 36\%a & 0,354 \\
Número de semanas para & (G I) 16,2a & 1,86 \\
consolidação & (G II) 13,9b & 1,73 \\
\hline
\end{tabular}

Para cada variável avaliada, médias seguidas de letras distintas na coluna diferem entre si $(\mathrm{P}>0,05)$
Tabela 2 - Medianas (quartis) segundo grupos (G I - pino intramedular e fixador tipo Ia; G II - pino intramedular e fixador externo em configuração "tiein") das variáveis avaliadas (grau de locomoção na retirada do fixador e Semana inicial de locomoção constante em grau IV).

\begin{tabular}{llll}
\hline & Mediana & Q1 & Q2 \\
\hline Grau de locomoção na retirada & (GI) 3,0 & 2,75 & 4,00 \\
do fixador & (GII) 2,0 & 2,00 & 4,00 \\
\multirow{2}{*}{$\begin{array}{l}\text { Semana inicial de locomoção } \\
\text { constante em grau IV }\end{array}$} & (GI) 9,0 & 5,8 & 13,3 \\
& 13,5 & 8,5 & 14,5 \\
\hline
\end{tabular}

Diferenças entre grupos para cada variável avaliada não foram significativas.

por LANGLEY-HOBBS et al. (1996). Apesar de o peso corpóreo final ter sido maior que o inicial, aparentemente, não ocorreu sobrecarga nas montagens, visto não ter sido detectada falência em quaisquer dos componentes. Além disso, não houve diferença estatística no ganho de peso entre os grupos, indicando que os dois tipos de configurações receberam cargas semelhantes. A remoção precoce do fixador esquelético externo tipo I representa uma vantagem em relação ao método "tie-in", já que os gatos devem ser mantidos em ambiente livre de obstáculos até a retirada dos aparelhos.

$\mathrm{O}$ emprego de pino intramedular menor que o diâmetro do istmo do canal medular, embora facilite a aplicação dos pinos transfixantes, como citado por ANDERSON \& ARON (1998), mostrou-se inadequado em relaçãoà estabilização, uma vezque, como apoio do membro, ocorreu translação do foco de fratura, isto é, cisalhamento horizontal, em quatro animais. O fixador externo, nestes casos, foi mais eficiente para evitar a instabilidade rotacional. Cabe salientar que a translação não impediu a consolidação das fraturas. Como referido por ARON \& DEWEY (1992), a estabilidade suficiente para a demanda biomecânica pode ser mais importante que a estabilidade absoluta. $\mathrm{O}$ aumento do número de pinos transfixantes por segmento provavelmente evitaria a ocorrência de translação já que promove maior rigidez da montagem (McPHERRON et al., 1992). Contudo, o desconforto e a lesão muscular poderiam ser acentuados (WHITEHAIR \& VASSEUR, 1992; JOHNSON\&HULSE, 2002).

Embora OLMSTEAD (1995) preconize a remoção do fixador externo com seis semanas, neste experimento, optou-se pela retirada com oito semanas porque os pinos externos possuíam ponta rosqueada de perfil positivo que permite maior fixação ao osso e menor afrouxamento. Segundo EGGER et al. (1993), somente após 12 semanas o uso da desestabilização não tem qualquer efeito benéfico na consolidação 


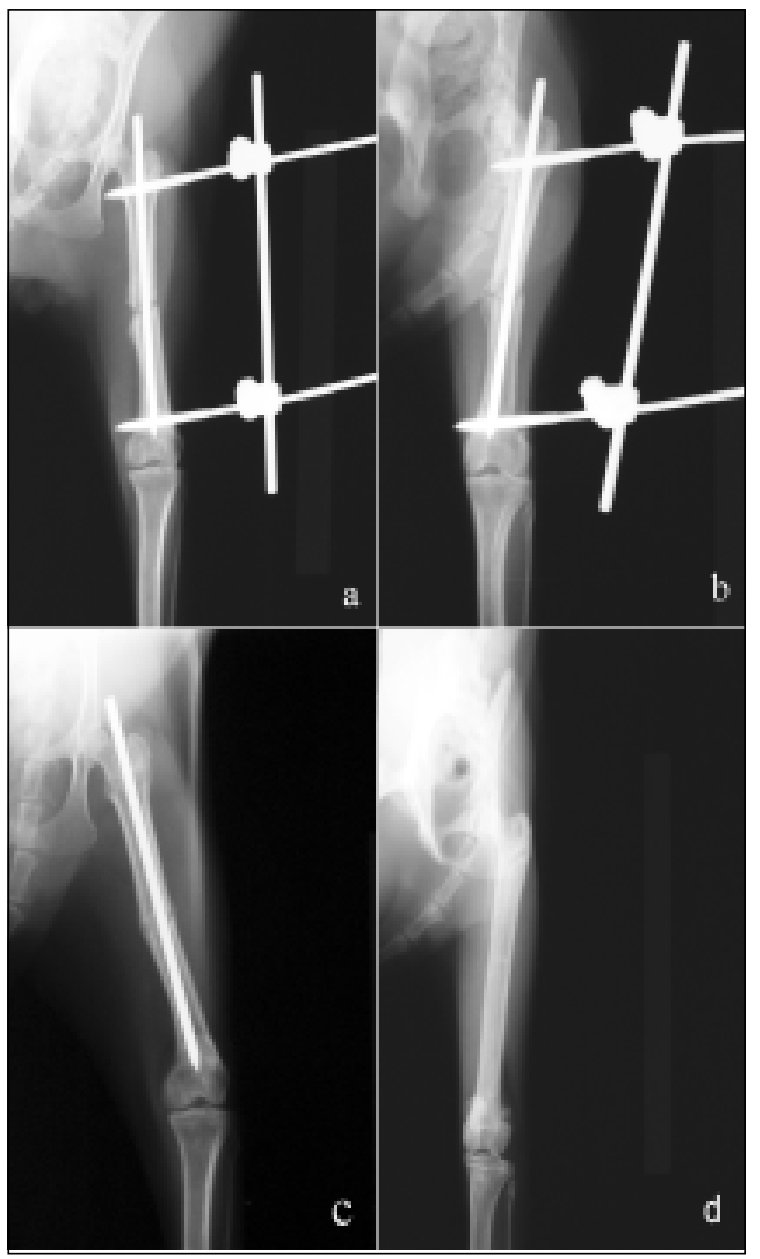

Figura 1 - Animal no 6 do grupo experimental I (pino intramedular e fixador externo tipo Ia). Aspecto radiográfico do fêmur, em posição craniocaudal, com quatro semanas (A), oito semanas ou época da remoção do fixador externo (B), 14 semanas (C) e 20 semanas ou último controle (D). Verifica-se a consolidação óssea com presença de calo periosteal mais evidente na face medial.

óssea. Por outro lado, observou-se que, em quatro animais do grupo experimental I, após a retirada do fixador externo ocorreu melhora no grau de apoio do membro, fato também citado por FOLAND et al. (1991). Dessa forma, a remoção com seis semanas poderia ter sido mais benéfica.

Amigração do pino intramedular, verificada em quatro animais do grupo experimental II, diferiu do citado por ARON et al. (1991), os quais verificaram que, com a configuração "tie-in", o pino intramedular é incapaz de migrar. O ocorrido pode estar associado ao afrouxamento do pino intramedular com o grampo conectante duplo ou ao assentamento inadequado do pino intramedular na extremidade distal. O afrouxamento pode ter relação com a carga mecânica imposta ao grampo conectante duplo, considerado menos resistente à deformação que o

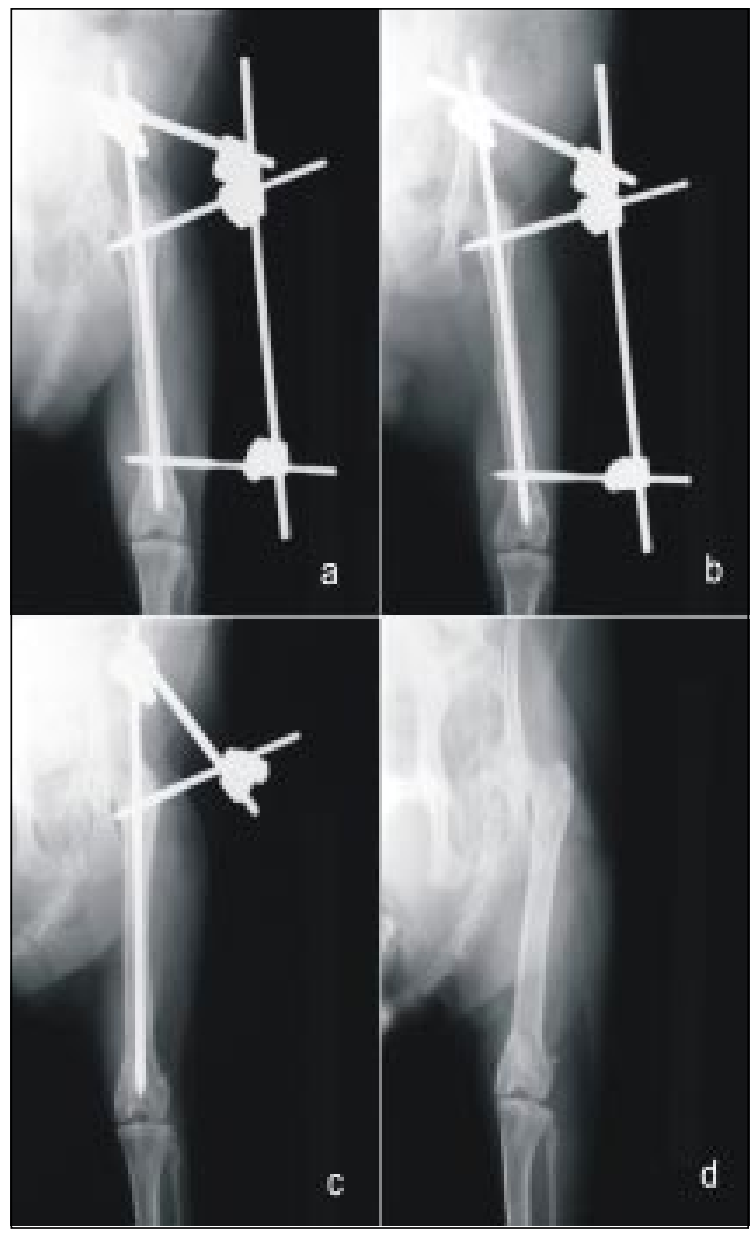

Figura 2 - Animal no 12 do grupo experimental II (pino intramedular e fixador externo em configuração "tiein"). Aspecto radiográfico do fêmur, em posição craniocaudal, com quatro semanas (A), oito semanas ou época da remoção do pino externo distal (B), 14 semanas ou época da remoção do fixador e pino intramedular (C) e 18 semanas ou último controle (D). Observa-se a consolidação óssea com discreta formação de calo ósseo periosteal na face medial do foco de fratura.

grampo simples, ao diâmetro do pino intramedular utilizado ou mesmo à força induzida para apertá-lo.

Os sinais clínicos apresentados por um animal do grupo I (6), no pós-operatório imediato, foram indicativos de lesão do ciático. Essa complicação, segundo PIERMATTEI \& FLO (1997), está associada à aplicação do pino intramedular de forma retrógrada, uma vez que, na forma normógrada, ele pode ser posicionado mais lateralmente na fossa trocantérica e longe da cabeça femoral e do nervo ciático. A locomoção alterada de dois gatos do grupo II (10 e 13) pode ter relação tanto com possível lesão nervosa como com penetração muscular pelo pino externo, visto ter ocorrido melhora acentuada, após a remoção de parte do fixador externo. 
Enquanto ARON et al. (1991) observaram reação tecidual mínima com o pino intramedular exposto na configuração "tie-in", cinco animais do grupo experimental II apresentaram secreção purulenta. Embora possa ter associação com o afrouxamento do pino com o grampo conectante duplo, o movimento pele-pino mais intenso nessa região é também um fator contribuinte para o processo. Além disso, deve ser considerado que, após a remoção do pino externo distal, tanto o pino intramedular como o pino externo proximal ficaram sob carga biomecânica maior, o que pode ter favorecido o afrouxamento.

A secreção mais acentuada verificada no pino externo distal, especialmente no grupo experimental I, pode ter relação com a maior mobilidade dessa região, por sua proximidade com o joelho, ou pelo posicionamento inadequado pele-pino. A osteólise ao redor dos pinos externos, visualizada radiograficamente, correspondeu em três casos com a secreção aumentada no trato dos pinos. Embora o pino externo de perfil positivo permita melhor rigidez e maior fixação ao osso (ARON \& DEWEY, 1992; PALMER et al., 1992; OLMSTEAD et al., 1995), teve como desvantagem a necessidade de aplicação de um pino intramedular de menor diâmetro.

Apesar de os métodos utilizados não terem as características de consolidação de um método rígido como a placa(ARON \& DEWEY, 1992; OLMSTEAD et al., 1995; JOHNSON\& HULSE, 2002), a pouca formação de calo ósseo sugere, como citado por JOHNSON et al. (1998), fixação estável. O calo periosteal mais evidente, aliado ao maior tempo para consolidação, é indicativo que a fixação do grupo experimental I foi menos rígida que no grupo II. Segundo OLMSTEAD et al. (1995), com um fixador flexível há maior proliferação de calo ósseo devido ao movimento interfragmentário. O fato de o calo periosteal ter sido, em ambos os grupos, mais visível na porção medial pode ter relação com a agressão cirúrgica mais lateral, tanto no acesso como na indução da fratura. Vale salientar que a densitometria óptica por imagens radiográficas não quantificou o volume do calo externo, mas mostrou que a densidade mineral óssea do calo ósseo externo foi semelhante entre os grupos.

A não-união hipertrófica verificada em um gato do grupo II (15) pode estar associada, de acordo com WHITEHAIR \& VASSEUR (1992), à neutralização inadequada das forças que atuam na fratura ou lesão no suprimento sangüíneo. A impossibilidade de retirada do pino intramedular em dois animais do grupo experimental I ( 3 e 5), uma vez que ele estava profundamente assentado, embora não represente complicação verdadeira, pode ser considerada uma desvantagem do método.

\section{CONCLUSÃO}

Independente da configuração utilizada, após a remoção dos implantes, todos os animais apresentam função normal do membro operado e a configuração "tie-in” proporciona consolidação óssea mais rápida que o pino intramedular e fixador esquelético tipo Ia.

\section{FONTES DE AQUISIÇÃO}

\author{
a - KIRSCHNER-EHMER (K-E) - Imex Veterinary - \\ Longview, Texas - USA. \\ b - INTERFACE ${ }^{\mathrm{TM}}$ Fixation Half-pins - Imex Veterinary - \\ Longview, Texas - USA.
}

\section{AGRADECIMENTOS}

Os autores agradecem à Fundação de Amparo a Pesquisa do Estado de São Paulo (FAPESP) pelo apoio financeiro e pela bolsa de Treinamento Técnico-Nível 3 concedida para Maria Isabel Garib durante a execução deste trabalho.

\section{REFERÊNCIASBIBLIOGRÁFICAS}

ANDERSON, M.A.; ARON, D.N. Repairing humeral and femoral fractures with external skeletal fixation. Vet Med, v.93, n.5, p.455-461, 1998

ARON, D.N. et al. Experimental and clinical experience with the IM pin/external skeletal fixator tie-in configuration. Vet Comp Orthop Traumatol, v.4, p. 86-94, 1991.

ARON, D.N.; DEWEY, C.W. Application and postoperative management of external skeletal fixators. Vet Clin North Am: Small Anim Pract, v.22, n.1, p. 69-97,1992.

EGGER, E.L. et al. Canine osteotomy healing when stabilized with decreasingly rigid fixation compared to constantly rigid fixation. Vet Comp Orthop Traumatol, v.6, p.182-187, 1993.

FOLAND, M.A.; SCHWARZ, P.D.; SALMAN, M.D. The adjunctive use of half-pin (type I) external skeletal fixators in combination with intramedullary pins for femoral fracture fixation. Vet Comp Orthop Traumatol, v.4, p.77-85, 1991.

JOHNSON, A.L. et al. Biomechanics and biology of fracture healing with external skeletal fixation. Comp Cont Educ Pract Vet, v.20, n.4, p.487-502, 1998.

JOHNSON, A.L.; HULSE, D.A. Fundamentals of orthopedic surgery and fracture management. In: FOSSUM, T.W. Small animal surgery. St. Louis : Mosby, 2002. Cap.33, p.821900 .

LANGLEY-HOBBS, S.J.; CARMICHAEL, S.; McCARTNEY, W. Use of external skeletal fixators in the repair of femoral fractures in cats. J Small Anim Pract, v.37, n.3, p.95-101, 1996.

LOUZADA, M.J.Q. Otimização da técnica de densitometria óptica em imagens radiográficas de peças óssea. Estudo "in vitro". 1994. 191f. Tese (Doutorado 
em Engenharia Biomédica) - Faculdade de Engenharia Elétrica, Universidade Estadual de Campinas.

McPHERRON, M.A.; SCHWARZ, P.D.; HISTAND, M.B Mechanical evaluation of half-pin (type 1) external skeletal fixation in combination with a single intramedullary pin. Vet Surg, v.21, n.3, p.178-182, 1992.

OLMSTEAD, M.L. Fractures of the bones of the hind limb. In: OLMSTEAD, M.L. Small animal orthopedics. St Louis: Mosby, 1995. Cap.9, p.219-243.

OLMSTEAD, M.L. et al. Principles of fracture repair. In: OLMSTEAD, M.L. Small animal orthopedics. St. Louis: Mosby, 1995. Cap.5, p.111-159.
PALMER, R.H. et al. Principles of bone healing and biomechanics of external skeletal fixation. Vet Clin North Am, Small An Pract, v.22, n.1, p.45-66, 1992 .

PIERMATTEI, D.L.; FLO, G.L. Fractures of the femur and patella. In:____. Handbook of small animal orthopedics and fracture repair. 3.ed. Philadelphia: Saunders, 1997. Cap.16, p.469-515.

WHITEHAIR, J.G.; VASSEUR, P.B. Fractures of the femur. Vet Clin North Am: Small Anim Pract, v.22, n.1, p.149158, 1992.

ZAR, J.H. Biostatistical analysis. New Jersey : Prentice Hall, 1996. 718p. 